\title{
ION EXCHANGE MONOLITHIC COLUMN FOR COPPER DETERMINATION
}

\author{
Ehab Fadhel Abed* and Ahmed Ali Alkarimi \\ Department of Chemistry, College of Science, University of Babylon, \\ Hilla, Iraq
}

\begin{abstract}
Glycidyl methacrylate-co-ethylene dimethcrylate-co- acryl amide monolithic column was synthesized as a strong cation exchange column. A borosilicate tube $(60 \mathrm{~mm}$ in length) with $1.5 \mathrm{~mm}$ and $3.0 \mathrm{~mm}$ (i.d and o.d respectively) was used for in-situ copolymerization using U.V light source. Monomers (glycidyle metharcrylate and acrylamide) and crosslinker ethylene dimethacrylate were dissolved in a porogenic solvent consisting of 1-propanol and 2-butanol. The polymer was formed after $4 \mathrm{~min}$. After that, the epoxy groups in glycidyle methacrylate were opened to form a cation exchange monolithic column by pumping $0.2 \mathrm{M} \mathrm{HCl}$. The monolith was characterized using diverse techniques such as FT-IR, BET, and FE-SEM. From FT-IR spectrum it can be noticed that the peak of $(\mathrm{C}=\mathrm{C})$ in the monomers and crosslinker are disappeared which is consider a significant indicator for polymer formation. The BET technique was used to investigate the pore size and surface area of the monolith, the result showed that the average pores size was $5.1859 \mathrm{~nm}$ and the surface area was $16.021 \mathrm{~m}^{2} / \mathrm{g}$. The FE-SEM technique was used to study the monolith morphology and the type of pore and the result proved that the monolith has a network of enormous channels and macroporse. The Prepared monolith in this study was used to remove copper ions and determine these ions using ion-exchange techniques.
\end{abstract}

Keywords: Monolith, Ion exchange column, copper, glycidyle metharcrylate

*Ehab Fadhel Abed, e-mail: ehabfadhel12@gmail.com 


\section{Introduction}

In recent years, were the industry growth, the accumulation of heavy metal ions that non-biodegradability will pose a threat to biota depending on their concentration range. ${ }^{1}$ Copper is one of the important elements that plays a significant role in daily life, for example, the development of red blood cells, bones, and many biological processes in human beings. ${ }^{2}$ In addition, it is required in a sufficient amount to avoid fatigue, slowed growth, iron insufficiency, brittle bones, and a weakened immune system due to copper deficiency.Whereas, high levels of copper will lead to big issues for human health. ${ }^{3}$

The polymeric monolith can be manufactured by preparing a polymerization mixture that includes the monomers, crosslinker, initiator, and porogenic solvent that can be polymerized by in-situ polymerization in a mold such as column, capillary tube, or microfluidic device, most of the polymerization methods are used radical polymerization, which is either UV radiation-activated or thermal- activated, the resulting polymeric monolith has continuous porous and it has the same advantages as the ordinary column in terms of $\mathrm{pH}$ and pressure stability. ${ }^{4-7}$

Polymeric monoliths have many applications one of these applications Ion-exchange chromatography. Ion-exchange chromatography is a chromatographic technique used to separate analytes substances depending on the electrostatic interaction between charged analytes and the opposing charges in the stationary phase. Then the ions are released from the stationary phase by competing ions of the same charge in the mobile phase. $^{8}$ There are two types of ion exchangers, anion-exchanger and cationic-exchanger depending on the charge of the functional groups in the stationary phase. ${ }^{9}$ Ion exchange column-based monolith could be used to 
separate small and large analytes, ranging from inorganic ions to biomacromolecules because it has some properties such as high flowrate, large surface area, minimal back-pressure and works in a wide range of $\mathrm{pH} .{ }^{10-14} \mathrm{In}$ addition, the retention time in the ion exchange column depends on the properties of the analyte, the ionic groups on the stationary phase, and the eluent's competing ions. ${ }^{8}$ This study aims to prepare monolithic column by free radical polymerization and study the effect of irradiation time on polymer formation and permeability. This work demonstrates that it is possible to separate and quantify copper ions in aqueous solutions easily and inexpensively compared to commercial columns.

\section{Experimental}

\section{Instruments}

UV-Visible spectrophotometer (UV-1700 double-beam Shimadzu, Japan) was used to record all the absorption spectra for the reagent and complex after eluting from the monolithic column by using a pair of $5 \mathrm{~mm}$ path length Quartz cells. Moreover, a digital analytical balance with high precision (Denever Instrument Germany TP-214) was utilized to weight all the samples. In addition, magnetic stirrer with heater (VWR West Chester, PA, USA) was used to mix all the components of the polymerization solution, Ultra sonic bath (India) was utilized to sonicate the polymer solution to remove any air bubbles that could be present in the solution. The homemade irradiation device $(220 \mathrm{~V}-50 \mathrm{HZ})$ was used to generate UV light that can be initiated the polymerization reaction. Syringe pump (Bioanalytical System Inc., USA) was used to pump the polymerization sample inside the borosilicate tube. HPLC pump with isocratic elution system (kd Scientific Holliston,MAU.S.A) was used to pump all the samples and solvents through the prepared monolithic column and HPLC 
system. The main peaks in the monomers, cross-linker, and the formed polymer were characterized using FT-IR 380 spectra (Bruker). The morphology of the monolith surface was investigated using FE-SEM (TESCAN, Model: Mira3, Czech Republic), while, the surface area and the pores size of the monolith was determined using BET technique (BEL, Model: BELSORP MINI II, Japan).

\section{Chemicals}

All the chemical that used in this work are analytical grade. Glycidyl methacrylate (GMA), acrylamide (A.Am), ethylene dimethacrylate (EDMA), 3-(trimethoxysilyl) propylmethacrylate, 2, 2-dimethoxy-2-phenyl acetophenone (DMPA) were purchased from (Sigma-Aldrich, Poole, UK). While, 1-Propanol, 2-Butanol, hydrochloric acid sodium hydroxide, nitric acid were purchased from (Gulf Cooperation Council). In addition, copper (II) nitrate $\mathrm{Cu}\left(\mathrm{NO}_{3}\right)_{2}$ was purchased from (BDH Middle East LLC), deionized water was used in all experiments.

\section{Preparation of (glycidyl methacrylate-co-ethylene dimethacrylate-co-acryl amide) monolithic column}

Fabrication of monolithic column was carried out by depending on the procedure published elsewhere with some modifications ${ }^{15}$ including monomers types according to the properties of a prepared monolith, in addition, the composition of porogenic solvent. However, firstly the borosilicate tube was silanized to ensure that the monolith attach to the inner surface of the borosilicate tube. After that, the polymerization solution was prepared by mixing $450 \mu \mathrm{L}$ (GMA) with $481.5 \mathrm{mg}$ (A.Am) and $50 \mu \mathrm{L}$ (EDMA) as cross-linker. (DMPA) with $1 \%$ from the weight of the monomers was used as an initiator. The porogenic solvent $(1000 \mu \mathrm{L}$ 
1-propanol $+650 \mu \mathrm{L}$ 2-butanol) was used to dissolve the monomers and crosslinker, In addition to the initiator. The polymerization mixture was mixed well for 10 min using a magnetic stirrer. After that, nitrogen gas is passed over the polymerization mixture to expel the oxygen, then the formed mixture was degassed by ultra-sonication for about $10 \mathrm{~min}$. Then the homogeneous solution was filled into the borosilicate tube and sealed at both ends with rubber stoppers. The polymerization process was initiated under UV light for $4 \mathrm{~min}$ (The distance between the column and the light source must be taken into account). In this work, the appropriate distance was $10 \mathrm{~cm}$, after monolith formation, the column was washed with ethanol and water to remove any unreacted component.

\section{Diol group formation}

The epoxy groups in glycidyl methacrylate were opened to form diol groups, this goal can be achieved using hydrolysis reaction with thermal activation at temperatures $(120-140) \mathrm{C}^{\circ}$ for long periods (24 hours). ${ }^{16,17}$ This time is very long so we reduced the time factor and avoided the high temperature (decrease the temperature make the hydrolysis occur smoothly) by using hydrochloric acid as a catalyst. ${ }^{18-20}$

\section{Results and discussion}

\section{Preparation of the monolithic column}

The ion exchange monolithic column was prepared using the UV polymerization process due to the advantages of this process over thermal polymerization. ${ }^{21}$ Glycidyl methacrylate was used as a primary monomer in polymer formation due to the epoxy group, this group(s) can be open easily to form different functional groups, these groups could be investigated to 
separate or immobilize or determine diverse compounds. ${ }^{22}$ In addition, the acrylamide monomer has an amine group that can be used to interact with other ions or compounds.

The first step in ion-exchange monolithic column formation was to silanized the inner surface of the borosilicate using 3-(trimethoxysilyl) propylmethacrylate, ${ }^{23}$ to attach the monolith to the inner surface of the tube and prevent the monolith to push out of the tube when used high flow rate. The silanization process is shown in Figure 1.

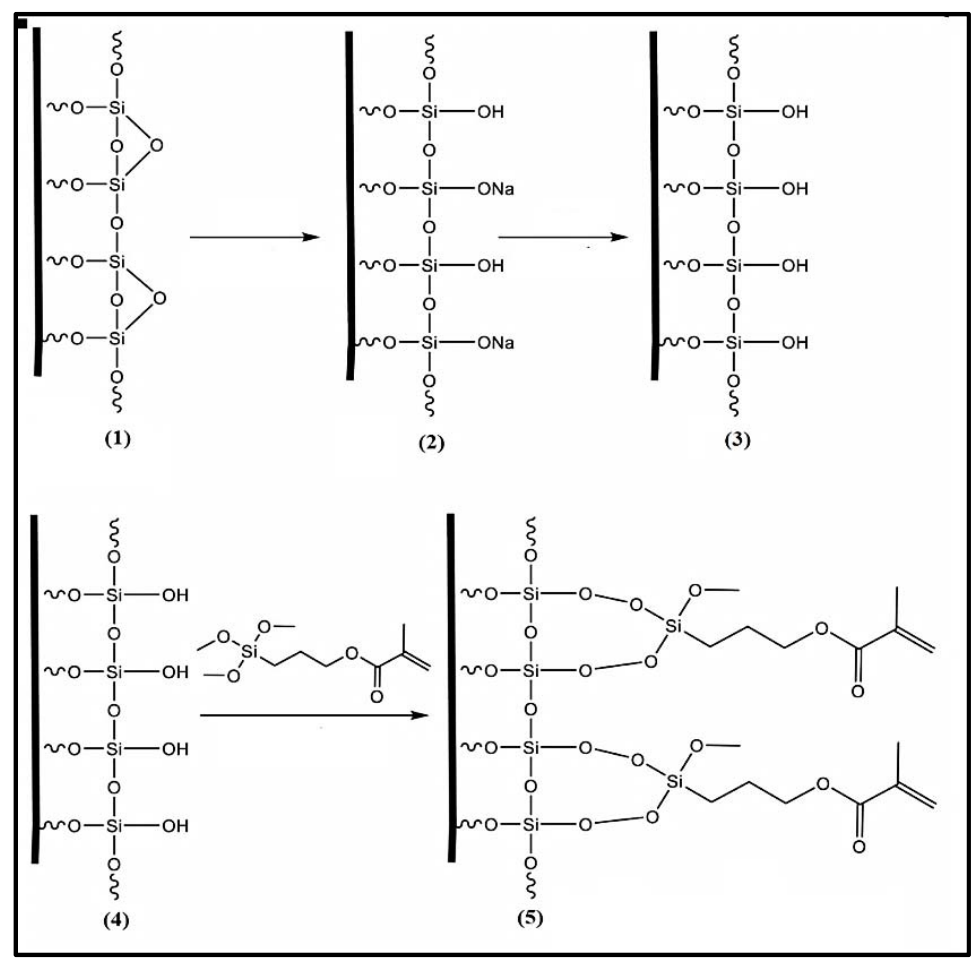

Figure 1. Silanization process of borosilicate tube, (1) is the inner wall of the borosilicate tube, (2) after addition of $0.2 \mathrm{M} \mathrm{NaOH}(5 \mu \mathrm{L} / \mathrm{min})$ for $1 \mathrm{hr}$., (3) after addition $0.2 \mathrm{M} \mathrm{HCl}$ (5 $\mu \mathrm{L} / \mathrm{min}$ ) for $1 \mathrm{hr}$., (4) after addition 3-(trimethoxysilyl) propylmethacrylate $(5 \mu \mathrm{L} / \mathrm{min})$ for $1 \mathrm{hr} .,(5)$ the inner wall after silanization process.

After the silanization step, the borosilicate tube was filled with polymerization solution described above, and polymerization step was carried out using a UV light source for initiation of the polymerization 
process by cleavage the initiator 2, 2-dimethoxy-2-phenyl acetophenone and forming free radical that attack the double bond in the monomers to form gycidyl methacrylate-co-ethylene dimethcrylate-co- acryl amide monolithic column.

\section{Effect of irradiation time}

The irradiation time is one of the main factors that can control the shape and the morphology of the monolith, due to increasing the branch of polymeric series and increase the surface area, and decreasing the pore size if the irradiation time was too long and vice versa. The irradiation time effect is (shown in Table 1).

Table 1. Effect of irradiation time.

\begin{tabular}{ll}
\hline $\begin{array}{l}\text { Irradiation } \\
\text { time (min) }\end{array}$ & $(50 \% \mathrm{GMA}, 50 \% \mathrm{~A} . \mathrm{Am})$ \\
\hline 1 & The monolith did not form \\
2 & The monolith did not form \\
3 & The monolith did not form \\
4 & The monolith formed with back pressure $33 \mathrm{Kg} / \mathrm{cm}^{2}$ \\
5 & The monolith formed but blocked \\
\hline
\end{tabular}

\section{Characteristics of the monolith}

Gycidyle methacrylate-co-ethylene dimethcrylate-co- acryl amide monolithic was characterized and identified using different techniques, for instance, scanning electron microscopy (SEM), BET, and FT-IR. To start with SEM the monolith's morphology exhibits significant cluster groups and macropores. The SEM image of a prepared monolith is (shown in Figure 2). 


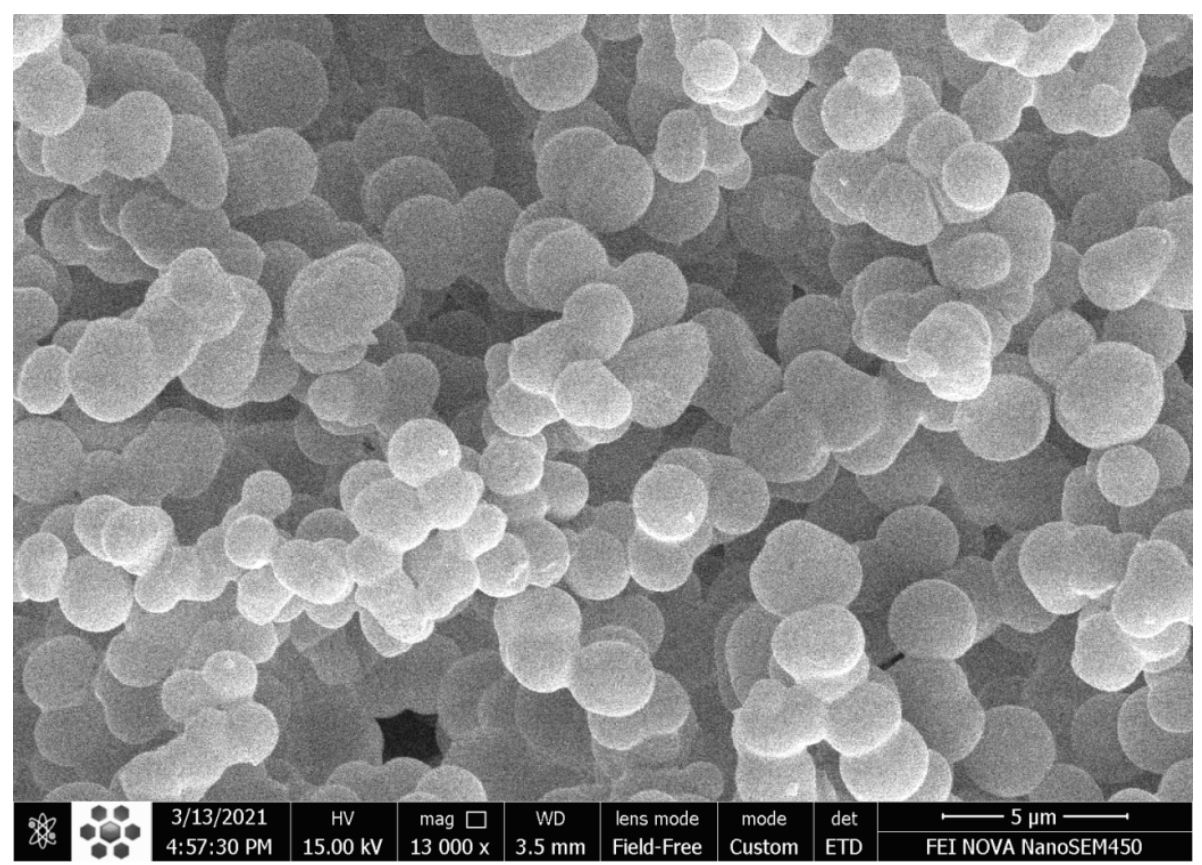

Figure 2. SEM image for the glycidyl methacrylate-co-acrylamide monolith.

Several necessary points for the prepared column can be deduced from Figure 2. Firstly, Monolithic media may be thought of as a network of enormous channels. ${ }^{24}$ Secondly, the mobile phase could be passed through these pores easily and this is useful in terms of reducing back pressure. ${ }^{24} \mathrm{On}$ the other hand the surface area of the monolith can be increased due to the micropores and mesopores, these pores can contribute to increase the surface loading ability of the monolith. Moreover, they increase the interactions when using a high flow rate and low back pressure. ${ }^{25}$

An FT-IR spectrum gives a clear indication of polymer formation by observing the main peaks in the monomers and the formed polymer. However, in the GMA monomer, the main peaks $1716.40 \mathrm{~cm}^{-1}$ for $(\mathrm{C}=\mathrm{O})$, $1636.98 \mathrm{~cm}^{-1}$ for $(\mathrm{C}=\mathrm{C}), 907.70 \mathrm{~cm}^{-1}$ for (epoxy ring), These peaks refer to the vibrational stretching of these functional groups. ${ }^{26}$ On the other hand the FT-IR spectra for A.Am showed main peaks for $(\mathrm{C}=\mathrm{C})$ at $1609.83 \mathrm{~cm}^{-1}$, $(\mathrm{C}=\mathrm{O})$ at $1666.02 \mathrm{~cm}^{-1}$, and $\left(\mathrm{NH}_{2}\right)$ at $3338.67 \mathrm{~cm}^{-1}$. 
The FT-IR spectra of GMA-co-EDMA-co-AAm showed clear peaks for $(\mathrm{C}=\mathrm{O}),\left(\mathrm{NH}_{2}\right)$, and epoxy ring. In the same time, the $(\mathrm{C}=\mathrm{C})$ peaks in the monomers and cross-linker spectra disappeared, this being a strong evidence of polymer formation. ${ }^{26}$

Brunauer-Emmett-Teller (BET) analyses demonstrate the surface area and the pore size of the gycidyle methacrylate-co-ethylene dimethcrylate-co- acryl amide monolithic column, the results were the pore size $(5.1859 \mathrm{~nm})$, while the surface area $\left(16.021 \mathrm{~m}^{2} / \mathrm{g}\right)$.

Ring-opening of glycidyl methacrylate-co-ethylene dimethacrylateco-acrylamide to form strong ion exchange monolithic columns.

When the monolith was prepared, the epoxy ring was opened by hydrolysis in the presence of hydrochloric acid as a catalyst. This step is carried out by pumping hydrochloric acid $(0.2 \mathrm{M})$ using a Dual syringe (flow rate $20 \mu \mathrm{L}$ ) for 3 hours.

The epoxy group was converted to diol groups, the ring-opening reaction and diol formation were demonstrated using FT-IR spectra that is shown in Figure 3.

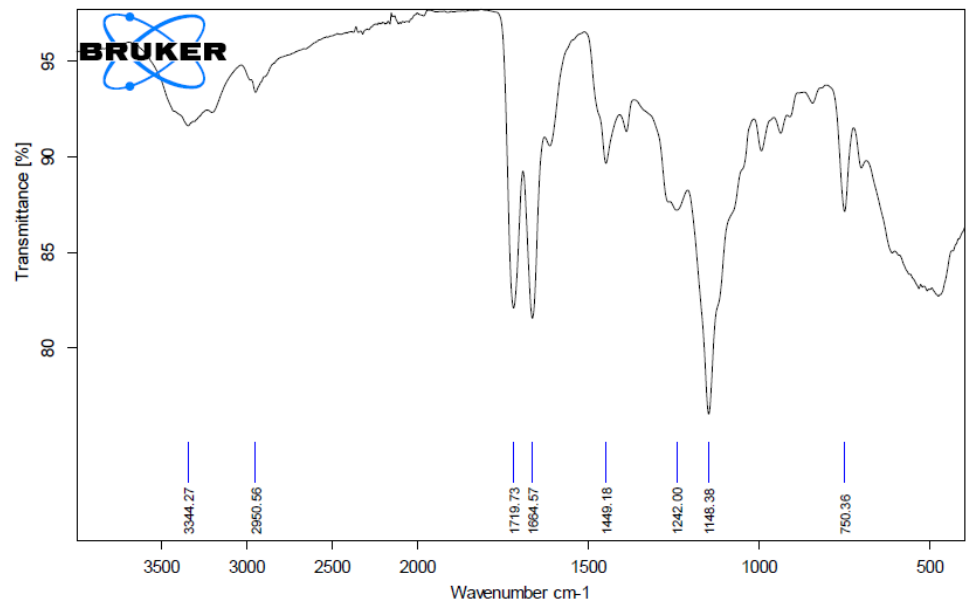

Figure 3. FT-IR spectra of the monolith after a ring-opening reaction.

From figure 3 it can be seen that the broad peak of the $\mathrm{OH}$ group at $\left(3344.27 \mathrm{~cm}^{-1}\right)$ which is an evidence of the epoxy ring opening, whereas this 
peak was not found in the FT-IR spectra of the monolith before the epoxy group opening.

\section{Calculation chelating capacity for monolith column}

A chelating capacity of the monolithic column can be calculated from the following Expression:

$$
\begin{gathered}
Q=\frac{C \times V}{W} \\
Q=\frac{1.68(\mathrm{mmol} . L-1) \times 0.0025(L)}{0.0956(\mathrm{~g})} \\
\mathrm{Q}=0.4 \mathrm{mmol} . \mathrm{g}^{-1} \\
=2.3 \mathrm{ppm}
\end{gathered}
$$

where $\mathrm{Q}$ is the adsorption capacity of the chelating monolith column, $\left(\mathrm{mmol} . \mathrm{g}^{-1}\right), \mathrm{V}$ is the volume of the eluate $(\mathrm{L}), \mathrm{C}$ is the concentration of $\left(\mathrm{M}^{2+}\right)$ in the eluate $\left(\mathrm{mmol} . \mathrm{L}^{-1}\right), \mathrm{W}$ is the dry weight of monolith inside the column $(\mathrm{g}){ }^{27}$ The result showed the chelating capacity is (2.3 ppm).

\section{Beers' Lambert Law}

Neocuproine reagent was used to determine the copper concentration after its reduction from $\mathrm{Cu}^{+2}$ to $\mathrm{Cu}^{+1}$ by using uric acid and modifying the $\mathrm{pH}$ of the solution in the range (7.5-8). ${ }^{28}$ A yellow complex formed when Neocuproine react with copper and the maximum absorbs of the complex was $455 \mathrm{~nm}$, Beers' Lambert law was applied to constrict the calibration curve in the range $(0.5-28 \mathrm{ppm})$ using the spectrophotometric method. A calibration curve is shown in Figure 4 and all calculated parameters are shown in Table 2. 


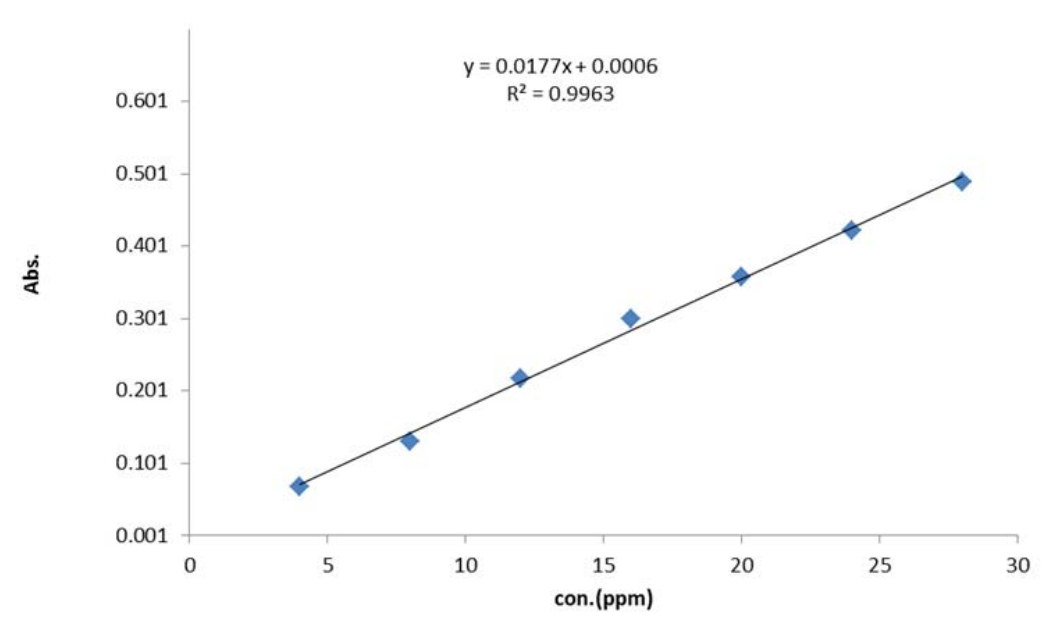

Figure 4. Calibration curve for spectrophotometric method.

Table 2. The parameters obtained from the calibration curve.

\begin{tabular}{l|l}
\hline Parameters & Values \\
\hline Range & $(0.5-28) \mathrm{ppm}$ \\
slop & 0.0178 \\
rmax & $455 \mathrm{~nm}$ \\
Intercept & 0.0007 \\
$\mathrm{R}^{2}$ & 0.9979 \\
LOD & 0.129 \\
LOQ & 0.353 \\
Sandle Index $\mu \mathrm{g} / \mathrm{cm}^{2}$ & 0.0561 \\
$\varepsilon(\mathrm{L} / \mathrm{mol.cm})$ & 8551.12 \\
\hline
\end{tabular}

\subsection{Application of glycidyl methacrylate-co-ethylene}

dimethacrylate-co-acrylamide as strong cation exchange monolithic column for $\mathrm{Cu}^{2+}$ determination

After column capacity was determined, a standard method was applied to investigate the capability of the column as strong cation exchange, However, 2 ppm $\mathrm{Cu}\left(\mathrm{NO}_{3}\right)_{2}$ solution has been pumped inside the column (flow rate $20 \mu \mathrm{L} \cdot \mathrm{min}^{-1}$ ). After that the column was washed with 
deionized water to remove any excess from copper, then $0.2 \mathrm{M} \mathrm{HNO}_{3}$ was pumped inside the column to elute attached copper from the column. The displaced copper was collected from a column and estimated using the spectrophotometric method that is described above. The concentration of eluting copper calculated using the spectrophotometric method was compared with the atomic absorption method to confirm the performance of the cationic exchange column; the results are shown in Table 3.

Table 3. The comparison between the calculated concentration of copper using spectrophotometric and atomic absorption method.

\begin{tabular}{lll}
\hline $\begin{array}{l}\text { Applied } \mathbf{C u} \\
\text { concentration }\end{array}$ & $\begin{array}{l}\text { Spectrophotometric } \\
\text { determination } \mathbf{n}=\mathbf{3}\end{array}$ & $\begin{array}{l}\text { Atomic absorption } \\
\text { determintion } \mathbf{n}=\mathbf{3}\end{array}$ \\
\hline $2 \mathrm{ppm}$ & $1.90 \mathrm{ppm}$ & $1.96 \mathrm{ppm}$ \\
\hline
\end{tabular}

\section{Conclusions}

GMA-co-EDMA-co-AAm monolithic polymer was prepared successfully in easy and inexpensive by in- situ polymerization inside the borosilicate tube to form cation exchanger. The prepared column was used for removing and estimating of copper ions. In addition, multiple degrees of permeability can be obtained by controlling the irradiation time. Therefore, the prepared monolithic column can be used with different flow rates with resendable back pressures without any problems related to the leak in any sealed parts in the HPLC system. The ring-opening reaction of epoxy group in GMA monomer could be opened new approaches for formation or modification different ion exchangers as desired. 


\section{References}

1. Rais, S.; Islam, A.; Ahmad, I.; Kumar, S.; Chauhan, A.; Javed, H. Preparation of a new magnetic ion-imprinted polymer and optimization using Box-Behnken design for selective removal and determination of $\mathrm{Cu}(\mathrm{II})$ in food and wastewater samples. Food Chemistry 2020, 334, 127563.

2. Versieck, J.; Comelis R. Trace elements in human plasma or serum. Boca Raton, FL: CRC Press Inc., 1989. pp.425.

3. Arredondo, M.; Núñez, M. T. Iron and copper metabolism. Mol. Aspects Med. 2005, 26(4-5), 313-327.

4. Viklund, C.; Svec, F.; Fréchet, J. M. J.; Irgum, K. Monolithic, "Molded", Porous Materials with High Flow Characteristics for Separations, Catalysis, or Solid-Phase Chemistry: Control of Porous Properties during Polymerization. Chem. Mater. 1996, 8(3), 744-750.

5. Svec, F.; Frechet, J. M. J. Temperature, a simple and efficient tool for the control of pore size distribution in macroporous polymers. Macromolecules 1995, 28(22), 7580-7582.

6. Viklund, C.; Pontén, E.; Glad, B.; Irgum, K.; Hörstedt, P.; Svec, F. "Molded" macroporous poly (glycidyl methacrylate-co-trimethylolpropane trimethacrylate) materials with fine controlled porous properties: preparation of monoliths using photoinitiated polymerization. Chem. Mater. 1997, 9(2), 463-471.

7. Geiser, L.; Eeltink, S.; Svec, F.; Fréchet, J. M. J. Stability and repeatability of capillary columns based on porous monoliths of poly (butyl methacrylate-co-ethylene dimethacrylate). J. Chromatogr. A 2007, 1140(1-2), 140-146.

8. Nordborg, A.; Hilder, E. F. Recent advances in polymer monoliths for ionexchange chromatography. Anal. Bioanal. Chem. 2009, 394(1), 71-84.

9. Fritz, J.S. Early milestones in the development of ion-exchange chromatography: a personal account. J. Chromatogr. A, 2004, 1039(1-2), 3-12.

10. Kastner, M.; Neubert, D. High-performance metal chelate affinity chromatography of cytochromes P-450 using chelating superose. $J$. Chromatogr. 1991, 587, 43-54. 
11. Levison, P. R. Large-scale ion-exchange column chromatography of proteins. J. Chromatogr. B 2003, 790(1-2), 17-33.

12. Tennikova, T. B.; Svec, F. High-performance membrane chromatography: Highly efficient separation method for proteins in ionexchange, hydrophobic interaction and reversed-phase modes. $J$. Chromatogr. A 1993, 646(2), 279-288.

13. Cabrera, K.; Lubda, D.; Eggenweiler, H.-M.; Minakuchi, H.; Nakanishi, K. A new monolithic - type HPLC column for fast separations. J. High Resolut. Chromatogr. 2000, 23(1), 93-99.

14. Haddad, P. R.; Nesterenko, P. N.; Buchberger, W. Recent developments and emerging directions in ion chromatography. $J$. Chromatogr. A 2008, 1184(1-2), 456-473.

15. Liu, D.; Zhang, T.; Cheng, Y.; Jia, Q. Poly (glycidyl methacrylate-co-Nmethylolacrylamide-co-ethylene dimethacrylate) monolith coupled to high-performance liquid chromatography for the determination of adenosine phosphates in royal jelly. J. Sep. Sci. 2014, 37(14), 1826-1833.

16. Jones, M.-C.; Tewari, P.; Blei, C.; Hales, K.; Pochan, D. J.; Leroux, J.C. Self-assembled nanocages for hydrophilic guest molecules. J. Am. Chem. Soc. 2006, 128(45), 14599-14605.

17. Gao, H.; Jones, M.-C.; Tewari, P.; Ranger, M.; Leroux, J.-C. Starshaped alkylated poly (glycerol methacrylate) reverse micelles: Synthesis and evaluation of their solubilizing properties in dichloromethane. J. Polym. Sci. A: Polym. Chem. 2007, 45(12), 24252435.

18. Gudipati, C. S.; Tan, M. B. H.; Hussain, H.; Liu, Y.; He, C.; Davis, T. P. Synthesis of poly(glycidyl methacrylate)-block-Poly (pentafluorostyrene) by RAFT: precursor to novel amphiphilic poly (glyceryl methacrylate)-block-poly (pentafluorostyrene). Macromol. Rapid. Commun. 2008, 29(23), 1902-1907.

19. Ma, Y.; Gao, H.; Gu, W.; Yang, Y. W.; Wang, Y.; Fan, Y.; Ma, J. Carboxylated poly(glycerol methacrylate)s for doxorubicin delivery. Eur. J. Pharm. Sci. 2012, 45(1-2), 65-72.

20. Gu, W.; Ma, Y.; Zhu, C.; Chen, B.; Ma, J.; Gao, H. Synthesis of crosslinked carboxyl poly(glycerol methacrylate) and its application for the 
controlled release of doxorubicin. Eur. J. Pharm. Sci. 2012, 47(3), 556563.

21. Huo, Y.; Schoenmakers, P. J.; Kok, W. T. Efficiency of methacrylate monolithic columns in reversed-phase liquid chromatographic separations. J. Chromatogr. A 2007, 1175(1), 81-88.

22. Benaglia, M.; Alberti, A.; Giorgini, L.; Magnoni, F.; Tozzi, S. Poly(glycidyl methacrylate): a highly versatile polymeric building block for post-polymerization modifications. Polym. Chem. 2013, 4(1), 124-132.

23. Peterson, D. S.; Rohr, T.; Svec, F.; Fréchet, J. M. J. Dual-function microanalytical device by in situ photolithographic grafting of porous polymer monolith: integrating solid-phase extraction and enzymatic digestion for peptide mass mapping. Anal. Chem. 2003, 75(20), 53285335.

24. Unger, K. K.; Skudas, R.; Schulte, M. M. Particle packed columns and monolithic columns in high-performance liquid chromatographycomparison and critical appraisal. J. Chromatogr. A, 2008, 1184(1-2), 393-415.

25. Hebb, A. K.; Senoo, K.; Bhat, R.; Cooper, A. I. Structural control in porous cross-linked poly(methacrylate) monoliths using supercritical carbon dioxide as a "Pressure-Adjustable" porogenic solvent. Chem. Mat. 2003, 15(10), 2061-2069.

26. Safa, K. D.; Nasirtabrizi, M. H. Ring opening reactions of glycidyl methacrylate copolymers to introduce bulky organosilicon side chain substituents. Polym. Bull. 2006, 57(3), 293-304.

27. Rahmi, D.; Takasaki, Y.; Zhu, Y.; Kobayashi, H.; Konagaya, S., Haraguchi, H.; Umemura, T. Preparation of monolithic chelating adsorbent inside a syringe filter tip for solid phase microextraction of trace elements in natural water prior to their determination by ICP-MS. Talanta 2010, 81(4-5), 1438-1445.

28. Da Silva, J. C.; Suarez, W. T.; de Oliveira Krambeck Franco, M. Flow injection spectrophotometric determination of methimazole in pharmaceuticals using a charge transfer complex $\mathrm{Cu}(\mathrm{I})$-neocuproine. $J$. Anal. Chem. 2018, 73(3), 243-248. 